\title{
Recriar-se de subjetividades críticas na formação e no trabalho interprofissional
}

\author{
Maria Raquel Gomes Maia Pires, Leila Bernarda Donato Gottems
}

\begin{abstract}
Resumo
O Recriar-se (arte, lúdico e tecnologias educativas na saúde) é uma linha de produção científica do Núcleo de Pesquisa em Promoção da Saúde e Projetos Inclusivos, pertencente ao Centro de Estudos Avançados e Multidisciplinares da Universidade de Brasília (Nesprom/Ceam/UnB). Nosso compromisso é produzir conhecimentos e tecnologias lúdico- educativas para a formação e a prática de profissionais de saúde e de outras áreas, com ênfase na reinvenção de subjetividades críticas em suas dimensões éticas, estéticas, epistêmicas, política e social. O objetivo do trabalho é relatar as experiências de pesquisas do Recriar-se no fomento de subjetividades críticas de estudantes e profissionais, aplicadas aos diversos cenários do ensino e do trabalho interprofissional. Trata-se de um relato de experiência em pesquisa, produção tecnológica e narrativas lúdico-educativas de abordagem interdisciplinar e multiprofissional oriunda da referida linha. Nos últimos sete anos, diversos projetos de pesquisas originaram três tecnologias lúdico-educativas (jogos de tabuleiro (IN)DICASUS, Banfisa e Violetas), assim como a série 'Didáticos-para-Recriar-se', contendo 38 produções oriundas das experiências de pesquisa, de ensino e de extensão, articuladas às manifestações da arte e do lúdico, com ricas possibilidades de reinvenção sensível, ética e política dos participantes.
\end{abstract}

Descritores: Educação profissional em saúde pública, Aprendizagem, Educação em enfermagem., Metodologia 